\title{
Highly Selective Reductive Cross-Amination between Aniline or Nitroarene Derivatives and Alkylamines Catalyzed by Polysilane- Immobilized Rh/Pt Bimetallic Nanoparticles
}

\author{
Aya Suzuki ${ }^{1}$ \\ Hiroyuki Miyamura \\ Shū Kobayashi* iD \\ Department of Chemistry, School of Science, The University of \\ Tokyo, Hongo, Bunkyo-ku, Tokyo 113-0033, Japan \\ Published as part of the 30 Years SYNLETT - Pearl Anniversary Issue
}

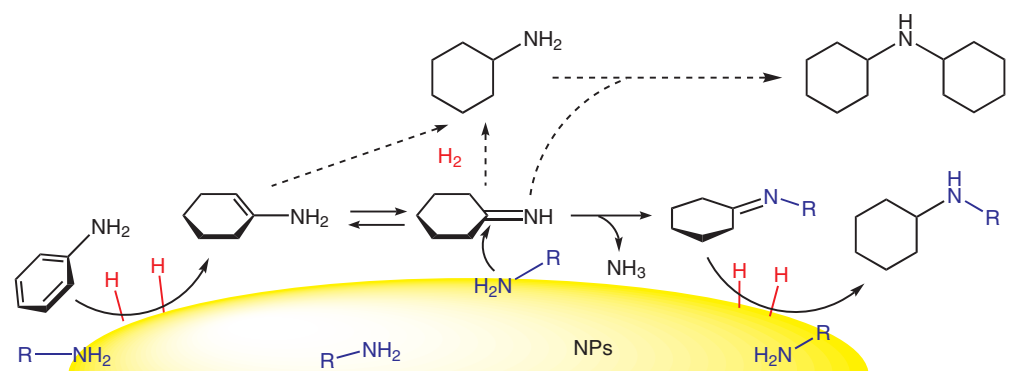

Received: 23.08 .20018

Accepted after revision: 17.10 .2018

Published online: 18.01.2019

DOI: 10.1055/s-0037-1611341; Art ID: st-2018-b0543-I

License terms: CCO

\begin{abstract}
Reductive cross-amination between imine intermediates generated through partial hydrogenation of aniline or nitroarene derivatives and alkylamines is an ideal method for obtaining $\mathrm{N}$-alkylated cyclohexylamine derivatives; however, no such transformations have hitherto been established. Here, we report a highly selective reductive cross-amination using aniline derivatives and alkylamines catalyzed by heterogeneous Rh/Pt bimetallic nanoparticles under mild conditions. The catalyst was recovered and reused for five runs, keeping high activity. In this reaction, imine intermediates generated during the course of partial hydrogenation of aniline derivatives were trapped immediately by strongly interacting primary alkylamines with the catalyst, which caused a highly selective transformation to give the desired products, while suppressing dicyclohexylamine formation.
\end{abstract}

Key words reductive amination, arene hydrogenation, heterogeneous catalyst, metal nanoparticle

Heterogeneous catalysts have attracted much attention because of their simple separation from products and their inherently reusable nature. In particular, metal nanoparticle (NP)-immobilized heterogeneous catalysts are of great interest because of their high reactivity, unique selectivity, and robustness. ${ }^{1}$ Our laboratory has developed polymerimmobilized metal NPs as heterogeneous catalysts, which have displayed promising reactivity tolerance, such as aerobic oxidation, ${ }^{2}$ tandem oxidative processes for ester or amide formation, ${ }^{3}$ and asymmetric $\mathrm{C}-\mathrm{C}$ bond-forming reactions. ${ }^{4}$ Recently, we reported a highly active polysilane-supported Rh/Pt bimetallic NP heterogeneous catalyst for arene hydrogenation. ${ }^{5}$ During the course of the hydrogenation of aniline catalyzed by the Rh/Pt NP-immobilized catalyst, we found that the reaction afforded not only cyclohexylamine, but also dicyclohexylamine in moderate yield. Inspired by this finding, we were fascinated by the possibility of a new methodology to obtain highly desirable alkylamines.

Amines are important and useful compounds for chemical synthesis. ${ }^{6}$ In particular, alkylamines are widely found in fine chemicals, pharmaceuticals, agrochemicals, and natural products. Reductive amination is a more reliable method to obtain alkylamines than the nucleophilic substitution of alkyl halides with primary amines, which sometimes suffers from overalkylation and coproduction of large amounts of useless inorganic salts. ${ }^{7}$

$\mathrm{N}$-Alkylated cyclohexylamine derivatives exhibit significant bioactivities, acting as, for example, anticonvulsants, kinase inhibitors, antidiabetics, and antiviral compounds. ${ }^{8}$ Recently, synthesis of $\mathrm{N}$-alkylated cyclohexylamine derivatives through hydrogenation of phenol in the presence of amines was reported (Scheme 1a). ${ }^{9}$ By contrast, synthesis of $\mathrm{N}$-cyclohexylaniline derivatives catalyzed by $\mathrm{Pd} / \mathrm{C}$, starting from nitroarenes, which are available in a wider range than phenol derivatives, was also reported (Scheme 1b). ${ }^{10}$ In these reactions, ketone or imine derivatives generated in situ through arene hydrogenation are utilized to react with amines. However, reductive cross-amination between externally added alkylamines and nitroarenes has not been reported because it was assumed that alkylamines were dehydrogenated to afford imines in the proposed reaction mechanism. ${ }^{9}$ Conversely, no dehydrogenation of an alkylamine was found with our Rh/Pt NP-immobilized catalyst in preliminary studies, suggesting that a partially reduced intermediate in the course of aniline hydrogenation reacted directly during dicyclohexylamine formation (Scheme 1c). In this context, we targeted hydrogenation of aniline and 
(a) Li and Vaccaro (2015)

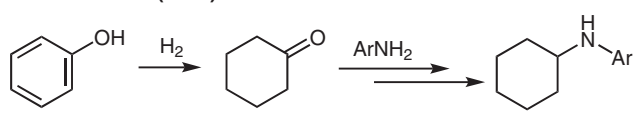

(b) Corma (2013)

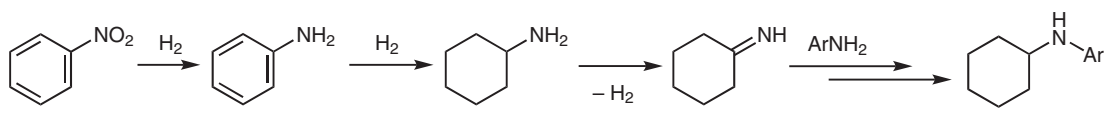

(c) This work

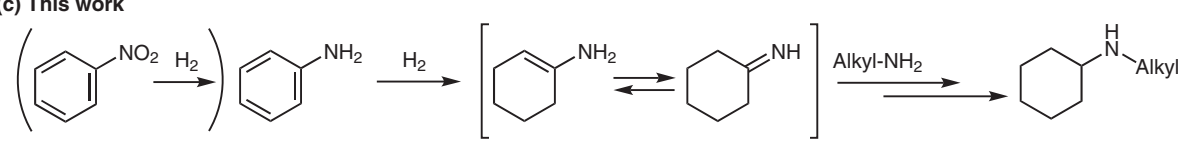

Scheme 1 Previous related work and present work

nitroarene derivatives in the presence of alkylamines to afford $\mathrm{N}$-alkylated cyclohexylamine derivatives through reductive cross-amination by direct utilization of imine intermediates that were generated through partial arene hydrogenation. In this reaction, reductive cross-amination would occur before dicyclohexylamine formation because amines interacting with the surface of the catalyst might trap unstable imine intermediates that are produced, immediately on the catalyst. Herein, we describe a highly selective reductive cross-amination using aniline derivatives and primary alkylamines catalyzed by metal NP-immobilized catalysts under mild conditions. To our knowledge, this is the first example of reductive cross-amination of alkylamines with aniline derivatives for the synthesis of $\mathrm{N}$-alkylated cyclohexylamine derivatives.

We commenced our study by investigating the reductive cross-amination with solvent screening using $n$-octylamine (1a) and 2 equivalents of aniline (2a) in the presence of a heterogeneous catalyst. For the catalyst, we used $\mathrm{Rh} / \mathrm{Pt}$ bi- metallic NPs immobilized on a nanocomposite support of dimethylpolysilane and alumina (DMPSi $/ \mathrm{Al}_{2} \mathrm{O}_{3}-\mathrm{Rh} / \mathrm{Pt}$ ), which was used in our previous report. Initially, polar solvents were examined. While THF gave a moderate yield, EtOH afforded the product in good yield (Table 1, entries 1 and 2). Meanwhile, almost none of the desired reaction products were obtained in DMF, which suffered from a low conversion of aniline, probably because of the strong interaction of DMF with the metal NPs (entry 3). Relatively polar solvents such as EtOAc and CPME gave moderate yields (entries 4 and 5). By contrast, hexane, which is a nonpolar solvent, afforded the desired product in the best yield (entry 6 ).

Reaction conditions were further optimized in hexane. A slightly larger amount of aniline gave the desired product in excellent yield (Table 2, entry 2). The catalyst loading was then lowered to $0.5 \mathrm{~mol} \%$, affording a lower yield (entry 3 ). We found that this transformation proceeded smoothly even when conducted in neat solvent (entry 4). In all cases,

Table 1 Effect of Solvents

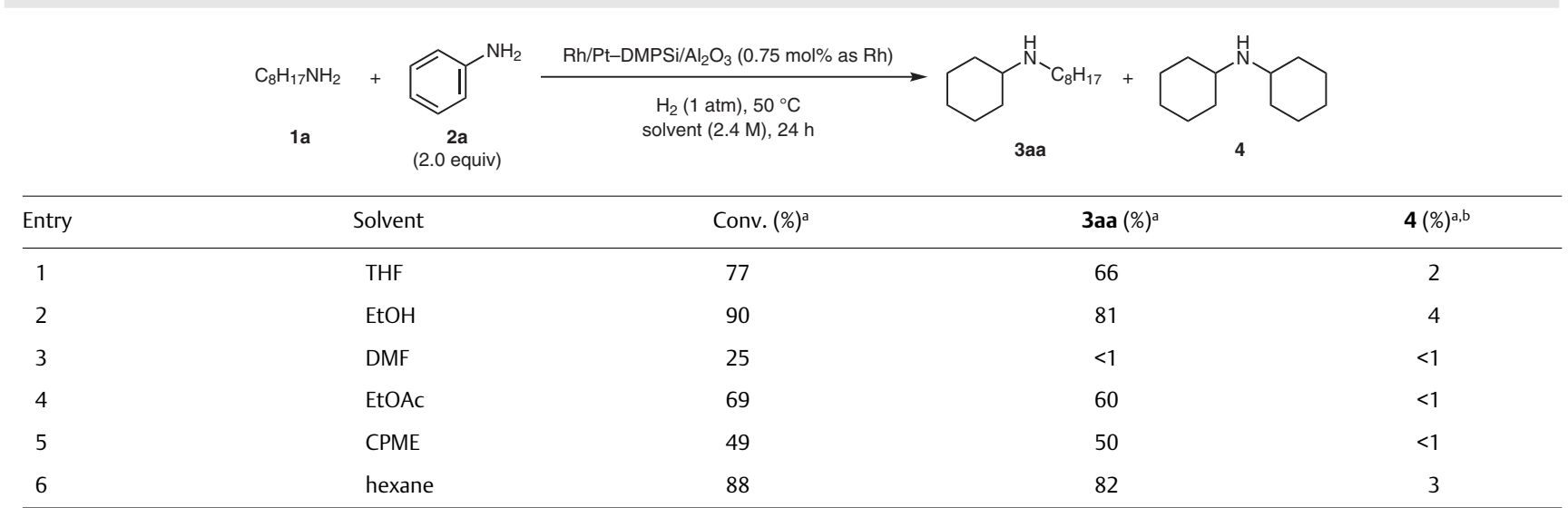

a Determined by GC analysis.

b Calculated based on used aniline. 
Table 2 Optimization of Reaction Conditions

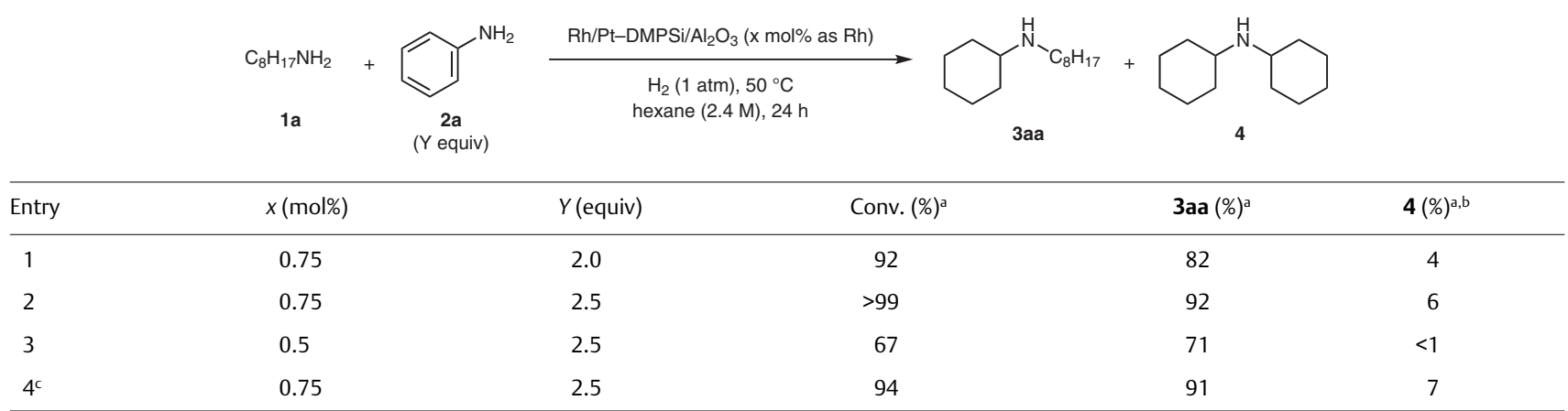

${ }^{a}$ Determined by GC analysis.

b Calculated based on used aniline.

c Reaction was conducted in neat solvent.

Table 3 Recovery and Reuse of DMPSi/Al ${ }_{2} \mathrm{O}_{3}-\mathrm{Rh} / \mathrm{Pt}$

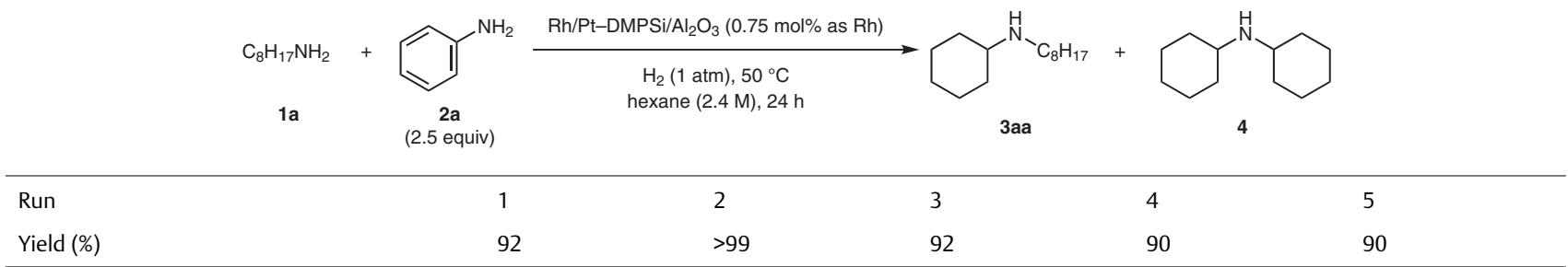

only a small amount of dicyclohexylamine $\mathbf{4}$ was generated as a by-product, indicating that the desired reaction would proceed through the expected pathway.

Recovery and reuse of DMPSi $/ \mathrm{Al}_{2} \mathrm{O}_{3}-\mathrm{Rh} / \mathrm{Pt}$ were then investigated. The catalyst was recovered by simple filtration of the reaction mixture and dried in vacuo at room temperature after washing with acetone and water. High yields were maintained for five runs (Table 3 ).

The generality of this transformation was tested under neat conditions. Various primary amines were reacted with aniline (2a). $n$-Hexylamine (1) $\mathbf{b})$ gave a quantitative yield (Table 4, entry 2). In the case of 3-phenylpropylamine (1c), the product was obtained in excellent yield without further reduction of the phenyl ring (entry 3). 3-Methoxypropylamine (1d) and mono-Boc-protected diamine (1e) were also acceptable (entries 4 and 5). Even tert-amine-containing substrate (1) $)$, which is assumed to strongly interact with the catalyst, afforded the product in quantitative yield (entry 6). The reductive cross-amination of $N$-methylaniline (2b) with n-octylamine (1a) also proceeded smoothly (entry 7). Furthermore, the desired product was obtained in good yield in the reaction with nitrobenzene (2c) (entry 8).

Here, we assume the mechanism of this reaction is as follows: Initially, partial hydrogenation of aniline by the catalyst affords an enamine, which gives an imine intermediate by isomerization. This imine is either trapped by a nucleophile or undergoes further hydrogenation to form cyclohexylamine. The trapping of the imine between an alkyl- amine and generated cyclohexylamine is competitive; an alkylamine affords the desired product while cyclohexylamine gives dicyclohexylamine as a by-product (Scheme 2). Considering the results of the mechanistic study in the previous report, ${ }^{5}$ it is assumed that the alkylamine is strongly adsorbed on the surface of the catalyst, which facilitates the rapid trapping of the imine intermediate generated on the surface of the catalyst by the alkylamine, leading to a high selectivity for the desired product over the by-product. To confirm this hypothesis, a mechanistic study was initiated.

To begin, reaction profiles were recorded to confirm adsorption of a primary amine to the catalyst surface by varying the amount of $n$-octylamine. A larger amount of $n$-octylamine ( 1.2 or $2.4 \mathrm{mmol}$ ) diminished the rate of the aniline hydrogenation compared with that obtained with a smaller amount of $n$-octylamine $(0.6 \mathrm{mmol})$ (Scheme 3$)$. These results indicate that n-octylamine is adsorbed on the surface of the catalyst and prevents the adsorption of aniline, which suppresses aniline hydrogenation. By contrast, when the rate of the product formation is compared, less $n$ octylamine gives the fastest reaction rate; in other words, a larger amount of $n$-octylamine, which suppresses aniline hydrogenation, and does not accelerate the reaction, suggesting that the aniline hydrogenation is the rate-determining step of this reaction. Furthermore, it was clearly observed that dicyclohexylamine started to form immediately after the complete consumption of the alkylamine when 0.6 $\mathrm{mmol}$ of the alkylamine was used (Scheme 4 ). These results 
Table 4 Substrate Scope of Reductive Cross-Amination ${ }^{11,12}$

\begin{tabular}{|c|c|c|c|c|}
\hline Entry & Amine & Electrophile source & Product $(c y=$ cyclohexyl) & Yield $(\%)^{\mathrm{a}}$ \\
\hline 1 & n-octylamine (1a) & aniline (2a) & $\begin{array}{l}\mathrm{Cy}^{-}{ }^{-}-\mathrm{C}_{8} \mathrm{H}_{17} \\
\text { 3aa }\end{array}$ & $93^{b}$ \\
\hline 2 & n-hexylamine (1b) & aniline (2a) & $\begin{array}{l}\mathrm{Cy}-{ }^{-}{ }^{-}-{ }^{6} H_{13} \\
\text { ba }\end{array}$ & $>99$ \\
\hline $3^{c}$ & 3-phenylpropylamine (1c) & aniline (2a) & $\begin{array}{l}\mathrm{Cy}- \\
3 \mathrm{ca}\end{array}$ & 92 \\
\hline $4^{\mathrm{d}}$ & 3-methoxypropylamine (1d) & aniline (2a) & $\mathrm{H}_{3}^{\mathrm{OMe}}$ & 97 \\
\hline 5 & tert-butyl $\mathrm{N}$-(6-aminohexyl)carbamate (1e) & aniline (2a) & $H_{6}^{\mathrm{NHBoc}}$ & 85 \\
\hline 6 & N,N'-dimethyl-1,6-hexanediamine (1f) & aniline (2a) & $y_{3}^{\mathrm{NMe}_{2}}$ & $>99$ \\
\hline 7 & n-octylamine (1a) & $\mathrm{N}$-methylaniline (2b) & $\begin{array}{l}C^{-1} \\
3 a a\end{array}$ & 89 \\
\hline 8 & n-octylamine (1a) & nitrobenzene (2c) & $\underset{3 a a}{\mathrm{Cy}^{-}-\stackrel{\mathrm{H}}{-{ }^{-}} \mathrm{C}_{8} \mathrm{H}_{17}}$ & 87 \\
\hline
\end{tabular}

a Isolated yield.

${ }^{b}$ Determined by GC analysis.

c $72 \mathrm{~h}$.

d $38 \mathrm{~h}$.

indicate that the alkylamine adsorbed on the surface of the catalyst prevented the dicyclohexylamine formation by trapping the imine intermediate immediately, leading to the high selectivity of the product.

In summary, we have achieved a highly selective reductive cross-amination using aniline derivatives and primary

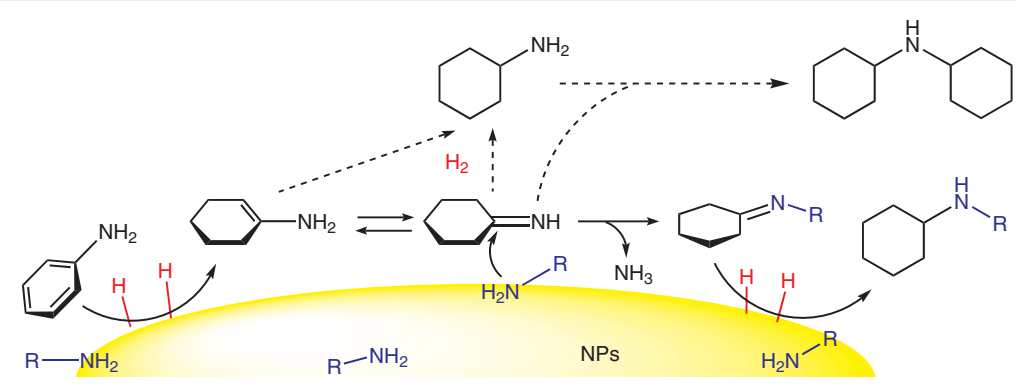

Scheme 2 Assumed reaction mechanism 

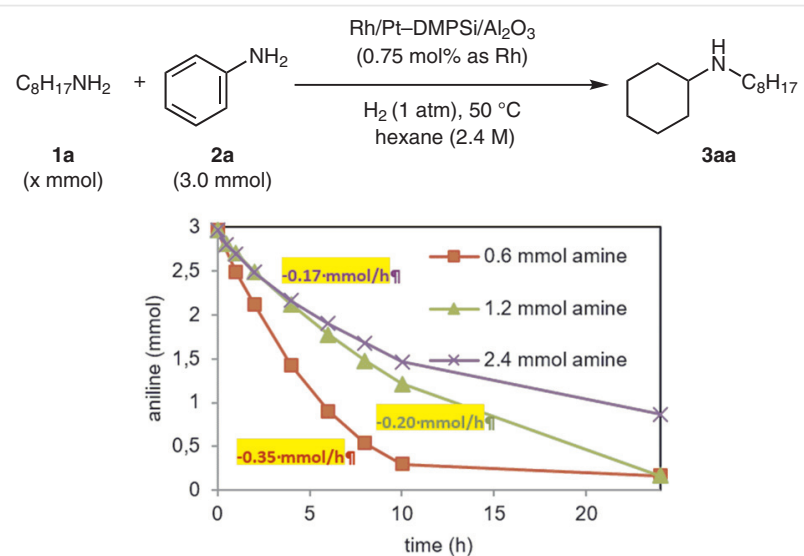

Scheme 3 Profile of conversion of aniline

alkylamines catalyzed by heterogeneous bimetallic NPs under mild conditions. Various primary alkylamines, such as simple alkyl amines, phenyl ring-containing amine, and tert-amine-containing amine afforded the desired products in high yields. In addition, the reaction was applicable to $\mathrm{N}$ alkylanilines and even nitroarenes. Furthermore, the catalyst was successfully recovered and reused by simple filtration while maintaining its high activity. In this reaction, imine intermediates generated during the course of partial hydrogenation of aniline derivatives reacted with primary alkylamines directly. In all cases, the desired cross-aminated products were selectively obtained before dicyclohexylamine derivatives, which could be generated through selfamination of aniline derivatives. It is assumed that primary alkylamines adsorbed on the surface of the catalyst trapped unstable imine intermediates immediately, which would lead to the highly selective transformation to give the desired products, while suppressing dicyclohexylamine formation. Further investigations on reductive cross-amination toward useful compounds such as drug precursors are ongoing.

\section{Funding Information}

This work was partially supported by a Grant-in-Aid for Science Research from the Japan Society for the Promotion of Science (JSPS), the Global COE Program, The University of Tokyo, Ministry of Education, Culture, Sports, Science and Technology (MEXT), Japan, and the Japan Science and Technology Agency (JST). A. S. thanks the JSPS fellowship for Japanese Junior Scientist.

\section{Supporting Information}

Supporting information for this article is available online at https://doi.org/10.1055/s-0037-1611341.

\section{References and Notes}

(1) Ding, K.; Uozumi, Y. Handbook of Asymmetric Heterogeneous Catalysis; Wiley-VCH: Weinheim, 2008.

(2) Kobayashi, S.; Miyamura, H. Aldrichimica Acta 2013, 46, 17.

(3) Miyamura, H.; Kobayashi, S. Acc. Chem. Res. 2014, 47, 1054.

(4) (a) Yasukawa, T.; Suzuki, A.; Miyamura, H.; Nishino, K.; Kobayashi, S. J. Am. Chem. Soc. 2015, 137, 6616. (b) Miyamura, H.; Suzuki, A.; Yasukawa, T.; Kobayashi, S. Adv. Synth. Catal. 2015, 357, 3815.

(5) Miyamura, H.; Suzuki, A.; Yasukawa, T.; Kobayashi, S. J. Am. Chem. Soc. 2018, 140, 11325.

(6) (a) Nugent, T. C. Chiral Amine Synthesis: Methods, Developments and Applications; Wiley: Hoboken, 2010. (b) Ricci, A. Modern Amination Methods; Wiley: Hoboken, 2008. (c) Breuer, M.; Ditrich, K.; Habicher, T.; Hauer, B.; Keßeler, M.; Stürmer, R.; Zelinski, T. Angew. Chem. Int. Ed. 2004, 43, 788.

(7) (a) Yin, Z.; Zeng, H.; Wu, J.; Zheng, S.; Zhang, G. ACS Catal. 2016, 6, 6546. (b) Kim, I.; Itagaki, S.; Jin, X.; Yamaguchi, K.; Mizuno, N. Catal. Sci. Technol. 2013, 3, 2397. (c) Lorentz-Petersen, L. L. R.; Jensen, P.; Madsen, R. Synthesis 2009, 4110. (d) Hollmann, D.; Bahn, S.; Tillack, A.; Beller, M. Chem. Commun. 2008, 3199. (e) Hollmann, D.; Bähn, S.; Tillack, A.; Beller, M. Angew. Chem. Int. Ed. 2007, 46, 8291. (f) Tillack, A.; Hollmann, D.; Michalik, D.; Beller, M. Tetrahedron Lett. 2006, 47, 8881.

(8) (a) Song, W.-H.; Liu, M.-M.; Zhong, D.-W.; Zhu, Y.-l.; Bosscher, M.; Zhou, L.; Ye, D.-Y.; Yuan, Z.-H. Bioorg. Med. Chem. Lett. 2013, 23, 4528. (b) Chen, T.; Takrouri, K.; Hee-Hwang, S.; Rana, S.;
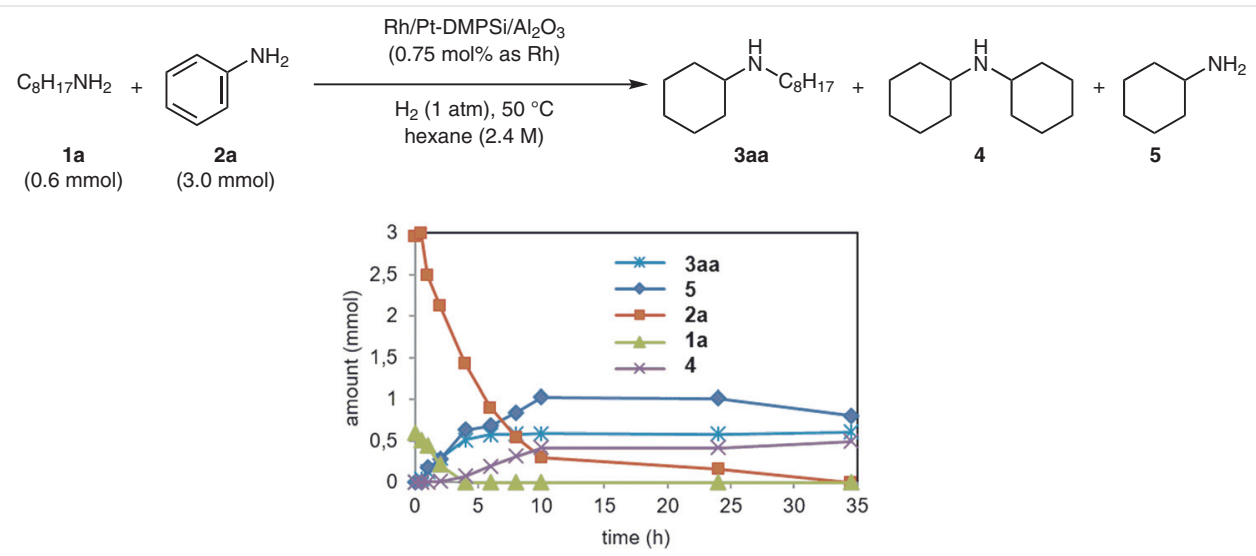

Scheme 4 Reaction profile 
Yefidoff-Freedman, R.; Halperin, J.; Natarajan, A.; Morisseau, C.; Hammock, B.; Chorev, M.; Aktas, B. H. J. Med. Chem. 2013, 56, 9457.

(9) (a) Jumde, V. R.; Petricci, E.; Petrucci, C.; Santillo, N.; Taddei, M.; Vaccaro, L. Org. Lett. 2015, 17, 3990. (b) Chen, Z.; Zeng, H.; Gong, H.; Wang, H.; Li, C.-J. Chem. Sci. 2015, 6, 4174. (c) Chen, Z.; Zeng, H.; Girard, S. A.; Wang, F.; Chen, N.; Li, C.-J. Angew. Chem. Int. Ed. 2015, 54, 14487. (d) Li, J.-S.; Qiu, Z.; Li, C.-J. Adv. Synth. Catal. 2017, 359, 3648.

(10) Rubio-Marques, P.; Leyva-Perez, A.; Corma, A. Chem. Commun. 2013, 8160 .

(11) $\mathrm{Rh}-\mathrm{Pt} /\left(\mathrm{DMPSi}-\mathrm{Al}_{2} \mathrm{O}_{3}\right.$ ) (33.4 mg, $0.75 \mathrm{~mol} \%$ as $\left.\mathrm{Rh}\right), n$-octylamine (1a) $(51.7 \mathrm{mg}, 0.4 \mathrm{mmol})$ and aniline (2a) $(74.0 \mathrm{mg}, 0.8 \mathrm{mmol})$ were placed in a Caroucel $^{\circledR}$ tube. The atmosphere was exchanged to $\mathrm{H}_{2}$ using a balloon and pump. The reaction mixture was stirred at $50{ }^{\circ} \mathrm{C}$ for $24 \mathrm{~h}$, then the reaction was quenched by the addition of EtOAc $(5 \mathrm{~mL})$ and the reaction mixture was analyzed by GC using decane as internal standard. Yield: $93 \%$; GC flow rate $(157.5 \mathrm{kPa}, \mathrm{He})$, Inject $\left(50^{\circ} \mathrm{C}\right)$, Detect $\left(100{ }^{\circ} \mathrm{C}\right)$, Int. $\mathrm{T}\left(50^{\circ} \mathrm{C}\right)$, Int. $\mathrm{T}(0 \mathrm{~min})$, Rate $\left(5^{\circ} \mathrm{C} / \mathrm{min}\right)$, Fin. $\mathrm{T}$ $\left(100{ }^{\circ} \mathrm{C}\right)$, Fin. $\mathrm{T}(10 \mathrm{~min}): t_{R}=30.068(N$-n-octylcyclohexylamine), 19.304 (decane internal standard) min.

(12) Rh-Pt/(DMPSi- $\left.\mathrm{Al}_{2} \mathrm{O}_{3}\right)(81.2 \mathrm{mg}, 0.75 \mathrm{~mol} \%$ as $\mathrm{Rh}), 3$-methoxypropylamine (1d) $(176.7 \mathrm{mg}, 1.2 \mathrm{mmol})$ and aniline (2a) (279.4 $\mathrm{mg}, 3.0 \mathrm{mmol}$ ) were placed in a Caroucel ${ }^{\circledR}$ tube. The atmosphere was exchanged to $\mathrm{H}_{2}$ using balloon and pump. After the reaction mixture was stirred at $50{ }^{\circ} \mathrm{C}$ for $38 \mathrm{~h}$, the reaction was quenched by the addition of $\mathrm{CH}_{2} \mathrm{Cl}_{2}(5 \mathrm{~mL})$. The catalyst was filtered off and the filtrate was concentrated. The desired product was isolated from the crude mixture by column chromatography (hexane/EtOAc/ $\left./ \mathrm{Et}_{3} \mathrm{~N}=3: 2: 0.1\right)$. Yield: $97 \% ;{ }^{1} \mathrm{H}$ NMR $(600 \mathrm{MHz}$, $\left.\mathrm{CDCl}_{3}\right): \delta=3.44(\mathrm{t}, J=6.2 \mathrm{~Hz}, 2 \mathrm{H}), 3.32(\mathrm{~s}, 3 \mathrm{H}), 2.71(\mathrm{t}, J=$ $6.9 \mathrm{~Hz}, 2 \mathrm{H}), 2.44-2.39$ (m, $1 \mathrm{H}), 1.87$ (d, $J=13.0 \mathrm{~Hz}, 2 \mathrm{H}), 1.77-$ $1.70(\mathrm{~m}, 4 \mathrm{H}), 1.63-1.59(\mathrm{~m}, 1 \mathrm{H}), 1.42(\mathrm{br}, 1 \mathrm{H}), 1.29-1.21$ (m, $2 \mathrm{H}), 1.19-1.14(\mathrm{~m}, 1 \mathrm{H}), 1.09-1.03(\mathrm{~m}, 2 \mathrm{H}) .{ }^{13} \mathrm{C} \mathrm{NMR}(100 \mathrm{MHz}$, $\mathrm{CDCl}_{3}$ ): $\delta=71.4,58.6,56.9,44.3,33.6,30.4,26.2,25.1$. IR (neat): $3579,3312,2928,2853,1672,1454,1375,1304,1255$, $1195 \mathrm{~cm}^{-1}$. HRMS (DART): $\mathrm{m} / z[\mathrm{M}+\mathrm{H}]^{+}$calcd for $\mathrm{C}_{10} \mathrm{H}_{22} \mathrm{NO}^{+}$: 172.17014; found: 172.16781 . 